\title{
Prevalence of anabolic steroid use in recreational users of gyms in the Monterrey metropolitan area
}

\author{
Oscar Salas-Fraire, Tomas J. Martínez-Cervantes, Arturo Rodriguez-Ochoa*, Yonny C. Carranza-Cervantes, \\ Iliana E. Quintero-Raygoza, Francisco Figueroa-Cavero, and Tomas D. Hernández-Lucero \\ Department of Sports Medicine and Rehabilitation, “Dr. Jose E. Gonzalez" University Hospital, Universidad Autónoma de Nuevo León, Monterrey, \\ Nuevo Leon, Mexico
}

\begin{abstract}
Objectives: The objectives of the study were to know the prevalence of consumption in the population of gyms in the metropolitan area of Monterrey, higher risk age group, reasons for consumption, sources of information, and adverse effects. Materials and methods: $A$ population of 316 male individuals over 18 years of age attending gyms in the metropolitan area of Monterrey who took anonymous surveys with 14 closed questions. This survey analyzed the variables: age, route of administration, anabolic consumed, reasons to consume, sources of information used, and adverse effects attributed to its use. Results: The prevalence was $17.2 \%$. Sources of information: coaches (59\%) and internet (21.1\%), reasons for consumption: physical performance (98.2\%) and esthetic (35.1\%). Adverse effects: About $91.1 \%$ of users presented adverse effects attributable to their use. Discussion: There is a clear prevalence of anabolic steroid (AS) consumption in the population, especially in those with more years of activity and taking more supplements. Conclusion: The consumption of ASs is more notable in the population with more years at the gyms, and these, for the most part, obtain information from unreliable means. Psychological disorders represent the most relevant short-term negative effects. Together, the above argues the need for the commitment of society in general to the prevention of and education in the use of ASs.
\end{abstract}

Key words: Anabolic steroids. Adverse events. Addiction. Doping. Muscle hypertrophy. Physical performance.

\section{Introduction}

Anabolic steroids (ASs) or anabolic androgenic steroids are synthetic substances linked to masculine sexual hormone androgens, that is, testosterone. This is clinically used to treat different conditions such as reproductive system dysfunction, breast cancer, and anemia. Nevertheless, currently, there are millions of men using AS around the world, many of which do not have athletic ambitions and wish to only increase and improve their physical strength and appearance ${ }^{1}$. In fact, studies suggest that elite athletes make up the smallest group of AS users. On the contrary, the highest levels of users were found among recreational athletes and those who use AS for occupational or cosmetic purposes ${ }^{2}$.

On the other hand, although ASs are non-narcotic or psychotropic drugs, their use in many cases falls into an abusive pattern in several sports. Therefore, the consumption of ASs for recreational, esthetic, or competitive purposes is considered by many psychiatrists as an addiction since it produces health and physical issues in both the short and long term. Some of the sequelae are linked to transformations caused by substances. Testosterone, for example, has androgenic effects such as prostate enlargement, alopecia or gynecomastia in men, and masculinization in women. In some cases, there are

\footnotetext{
Correspondence:

*Arturo Rodriguez-Ochoa

E-mail: drarturoochoa@gmail.com

Available online: $30-10-2020$

Date of reception: 19-11-2019

DOI: 10.24875/RMU.20000143

Medicina Universitaria. 2020;22(3):95-100 www.medicinauniversitaria.org

1665-5796/@ 2020 Universidad Autónoma de Nuevo León. Published by Permanyer. This is an open access article under the CC BY-NC-ND license (http://creativecommons.org/licenses/by-nc-nd/4.0/).
} 
also mental sequelae like psychosis, causing eating disorders in men who worry obsessively about their physical aspect as a result of a distortion of their body

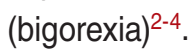

The prevalence of the use of AS around the world is sparsely documented, and the geographic distribution of these studies is limited mainly to the U.S., Canada, Brazil, and some European countries ${ }^{5}$. Therefore, the objective of this study was to determine the prevalence of the consumption of ASs among gym users in the metropolitan area of Monterrey, Mexico.

\section{Materials and methods}

An observational, descriptive, transversal study was carried out where we analyzed surveys conducted at 10 different gyms in the metropolitan area of Monterrey.

The data collection instrument was an anonymous and confidential questionnaire administered by an interviewer and presented as part of a research on the habits of athletes. The objective was to avoid defensive behavior from interviewees, leading the questions toward distractors to be able to ask about possible consumed substances. These were conducted during breaks or at the end of the physical activity of each individual.

The survey consisted of 14 questions, mostly closed questions with dichotomous categories or multiple choice; the latter included the possibility of several answers in the same question. There were eight variables, AS consumer rate among the studied population, age, route of administration (oral, injected), and type of substance consumed, reason why they began consuming, most frequently used sources of information, predominant physical activity in consumers, and adverse effects attributable to the use of said substances within the studied population (Fig. 1).

\section{Sample size determination}

Calculations to determine sample size were performed using a formula of rate estimation for an infinite population, expecting a prevalence between $5 \%$ and $8 \%$ of amateur users of the gym. With a unilateral confidence of $95 \%$, a precision of \pm 5 , a potency of $80 \%$, and $a Z=1.96$ were established, requiring at least 316 subjects for the study. This calculation was determined based on the parameters established in the literature and by the researcher.

\section{Statistical analysis}

Categorical variables will be presented with frequencies and percentages, with averages and standard deviations in the case of data with normal distribution, and medians, highs, and lows for non-parametric cases. The link between categorical variables will be analyzed with the Chi-square test. Comparisons between two independent groups of numerical variables will be conducted using the Student's t-test for independent samples or MannWhitney U or Wilcoxon tests. For statistical analysis, we used the SPSS Statistics software, version 25 (IBM, Armonk, New York, US).

\section{Results}

A total of 316 surveys were conducted in 10 gyms in the metropolitan area of Monterrey, with an average age of $29.6 \pm 6.8$ years. The prevalence of AS consumption in the studied population was $17.2 \%$. Regarding the type of physical activity performed by consumers, results showed that $99 \%$ practiced body building exercises (muscle potency and resistance), $33 \%$ additionally performed physical activities such as running and spinning.

The ASs consumed by the interviewees were testosterone $(100 \%)$, Dianabol $(86 \%)$, nandrolone $(80.7 \%)$, and dihydrotestosterone (82.5\%).

Of the population of $98.2 \%$ who consumed AS, they also consumed other substances or combinations of drugs to counteract possible side effects (Fig. 2). Most users referred to consuming said drugs in a combined manner.

Regarding the sources where the users obtained their information on instructions for the use of androgenic ASs, study results are found in figure 3 . It is worth noting that in most cases, the individuals involved went to different sources of information in a complementary manner.

Concerning the consumption pattern, our study shows that $96.5 \%$ performed it intramuscularly and $68.4 \%$ through tablets. Doses were taken through cycles with rest periods $(8.8 \%)$, full cycles $(22.8 \%)$, and randomized cycles $(10.5 \%)$ and combined cycles $(73.7 \%)$, with the latter the most predominant. The reasons for using androgenic AS are shown in figure 4; most surveyed referred to two or more reasons simultaneously.

Finally, obtained data suggest that $91.1 \%$ of users presented adverse effects attributable to the use of AS (Fig. 5). Only 4.7\% presented an isolated adverse effect, while $95.3 \%$ presented more than 1 adverse effect. 


\begin{tabular}{|c|c|c|c|c|}
\hline Age & & & & \\
\hline 1. ¿Do you perform any physical activity & & & Yes & No \\
\hline \multicolumn{3}{|c|}{ 2. What type of physical activity do you perform? } & & \\
\hline running & ( ) & & & \\
\hline weightlifting & ( ) & & & \\
\hline spinning & (1) & & & \\
\hline other. Specify. & (1) & & & \\
\hline 3. How long have you practiced it? & & & & \\
\hline \multicolumn{3}{|c|}{ 4. Do you consume any product to improve you performance? } & & \\
\hline \multicolumn{2}{|l|}{ 5. What type of product? } & & & \\
\hline energy drink & ( ) & creatine & ( ) & \\
\hline multi vitamin & ( ) & anabolic & ( ) & \\
\hline protein & & other & ( ) & \\
\hline \multicolumn{5}{|c|}{ 6. If you consume an anabolic, specify which one. } \\
\hline testosterone & ( ) & dihydrotestosterone & ( ) & \\
\hline dianabol & ( ) & nandrolone & ( ) & \\
\hline other & & & & \\
\hline \multicolumn{5}{|c|}{ 7. In case of use, do you combine it with otehr products? If so, which ones? } \\
\hline antiestrogens (clomifeno, tamoxifeno) & ( ) & gonadotrophin & ( ) & \\
\hline hepatic protectores & ( ) & other & ( ) & \\
\hline \multicolumn{3}{|l|}{ 8. What is the form of consumption? } & & \\
\hline Pills or capsules & ( ) & through the vein & ( ) & \\
\hline in the muscle & (1) & on the skin & (1) & \\
\hline \multicolumn{2}{|l|}{ 9. What is your consumption pattern? } & & & \\
\hline full cycles & ( ) & combined cycles & ( ) & \\
\hline random use & (1) & on-demand use & (1) & \\
\hline use with resting periods & ( ) & other & (1) & \\
\hline \multicolumn{4}{|c|}{ 10. Through which source did you obtain information on the use of this product? } & \\
\hline Trainer & ( ) & nutritionist & ( ) & \\
\hline internet & ( ) & pharmaceutic & ( ) & \\
\hline physician & ( ) & other & ( ) & \\
\hline \multicolumn{4}{|c|}{ 11. How long have you been consuming? Indicate with numbers. } & \\
\hline days & $\longrightarrow$ & & & \\
\hline months & 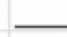 & & & \\
\hline years & & & & \\
\hline \multicolumn{4}{|c|}{ 12. Why did you decide to begin consumption? } & \\
\hline aesthetics & ( ) & health & (1) & \\
\hline physical performance & ( ) & other & (1) & \\
\hline \multicolumn{4}{|c|}{13 Did you observe any negative effect after consuming? If so, which one? } & \\
\hline acne & ( ) & diarrhea & ( ) & \\
\hline lower sex drive & ( ) & mood swings & ( ) & \\
\hline greater sex drive & ( ) & increase on chest tis & e( ) & \\
\hline erectile problems & ( ) & retention of liquids & ( ) & \\
\hline loss of hair & ( ) & other & ( ) & \\
\hline
\end{tabular}

Figure 1. Survey applied to research subjects.

An inferential statistical analysis was conducted, finding a significant difference in the age of patients who consume AS compared to those who did not consume, as well as in the amount of years performing physical activity and the number of products used to improve physical performance (Table 1).

\section{Discussion}

The present study shows the extensive use of AS in the surveyed gyms in different parts of Monterrey, including an affluence of people from different economic statuses. The main reasons for AS use are its apparent easy disposition and acquisition by those who wish to use them mainly as coadjutants in improving their physical performance and the changes in body composition linked to their use, without worrying about the possible harmful side effects which these may bring.

The proliferation of the black market for ASs as well as social media calls for improved ways of managing the public health problem that ASs represent worldwide ${ }^{6}$. The rise in the use of AS has been observed in previous studies, which even found a higher prevalence of $39.3 \%$ in comparison to our study, and the main reason for the use of AS there was esthetic, just as in our study? ${ }^{7}$. We are also able to see this increase in demand in our study, 


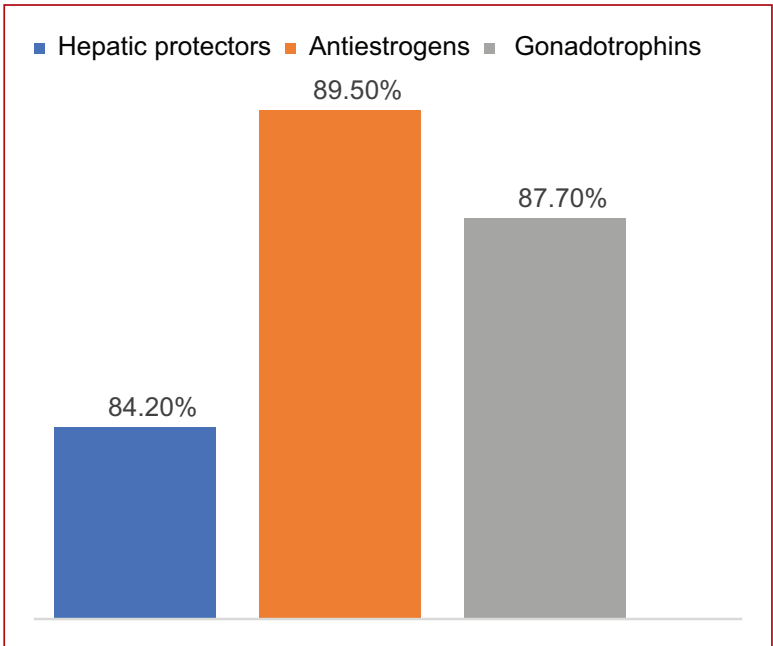

Figure 2. Drug used by study subjects to counteract possible side effects. The number of responses is not equal to the number of respondents since users had the option to choose more than 1 answer. Therefore, the response rate may exceed $100 \%$.

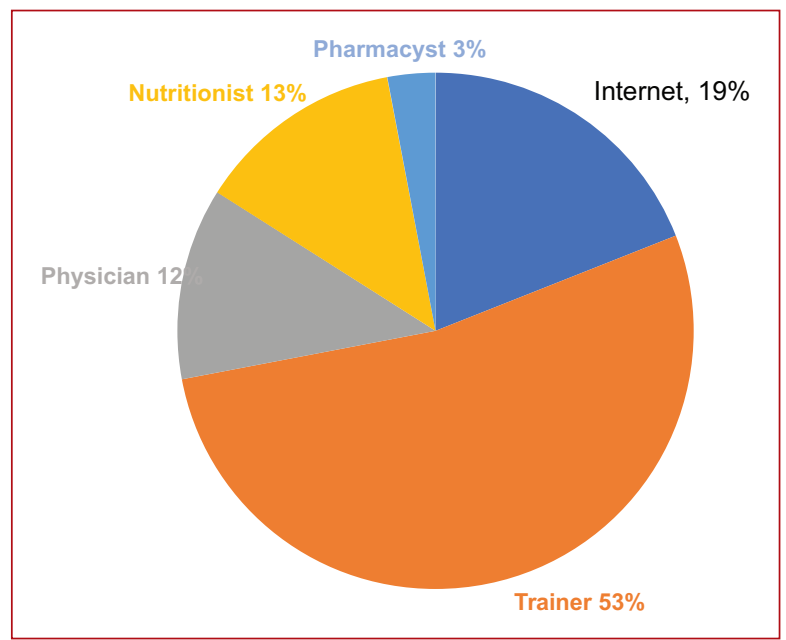

Figure 3. Means by which the study subjects obtained information for their use.

where we obtained a high prevalence in the consumption of AS in the studied population of $17.2 \%$, which in comparison to the previous studies were very high. Global prevalence in Sagoe et al. meta-analysis is $33 \%{ }^{8}$.

It is important to highlight the fact that the collected data suggest that in most cases, information on AS consumption is obtained from non-adequate resources, leaving to the bottom of the list the most reliable sources such as physicians, nutritionists, or pharmacists. On the other hand, the professionals consulted indicated that

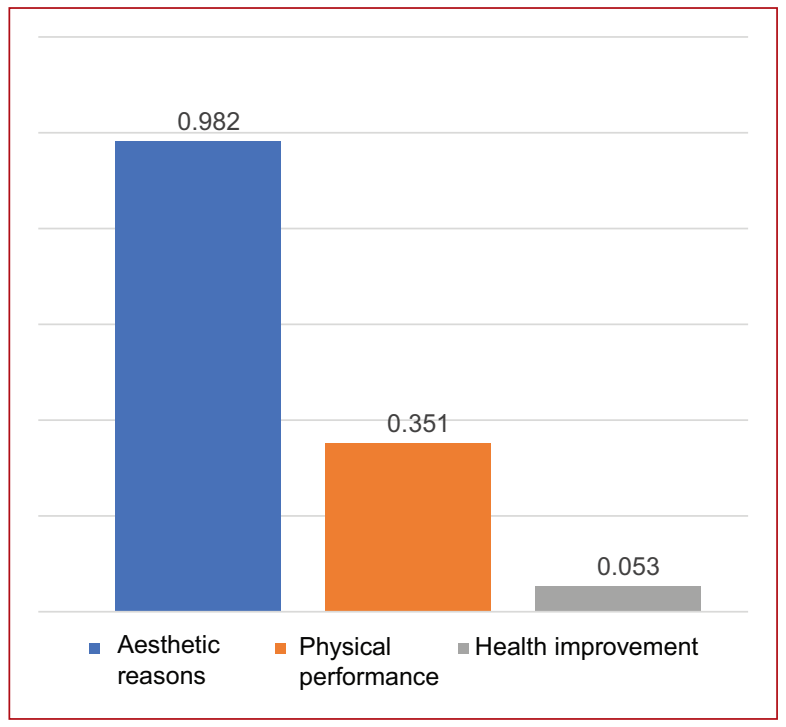

Figure 4. Reasons why study subjects used anabolic steroids. The number of responses is not equal to the number of respondents since users had the option to choose more than 1 answer. Therefore, the response rate may exceed $100 \%$.

Table 1. Comparison of variables between consumers and non-consumers of AS

\begin{tabular}{|l|c|c|c|}
\hline Variable & No num. (\%) & Yes num. (\%) & p value \\
\hline Age (SD) & $28.9(6.7)$ & $32.6(6.2)$ & 0.001 \\
\hline Time doing activity & $3.2(3)$ & $9.57(5.2)$ & 0.015 \\
\hline Running & 14.3 & 33.3 & 0.001 \\
\hline Weights & 97.3 & 99.3 & 0.317 \\
\hline Cycling & 5 & 7 & 0.545 \\
\hline Total of products & $1.6(1.2)$ & $4(0.7)$ & 0.001 \\
\hline Energy drinks & 10.8 & 33.3 & $<0.001$ \\
\hline Multivitamins & 33.6 & 93 & $<0.001$ \\
\hline Protein & 76.8 & 91.2 & 0.015 \\
\hline Creatinine & 39.8 & 96.5 & $<0.001$ \\
\hline
\end{tabular}

AS: anabolic steroid, SD: standard deviation

the use of said substances, when not for medical reasons, has negative health implications. It is fundamental to stress that in recent years, there has been a significant increase in the search for information through the internet, which is known to be unreliable because of its inadequate regulation of data published, with a high amount of information found not properly selected by users or organisms with proper scientific credentials ${ }^{7,9}$. 


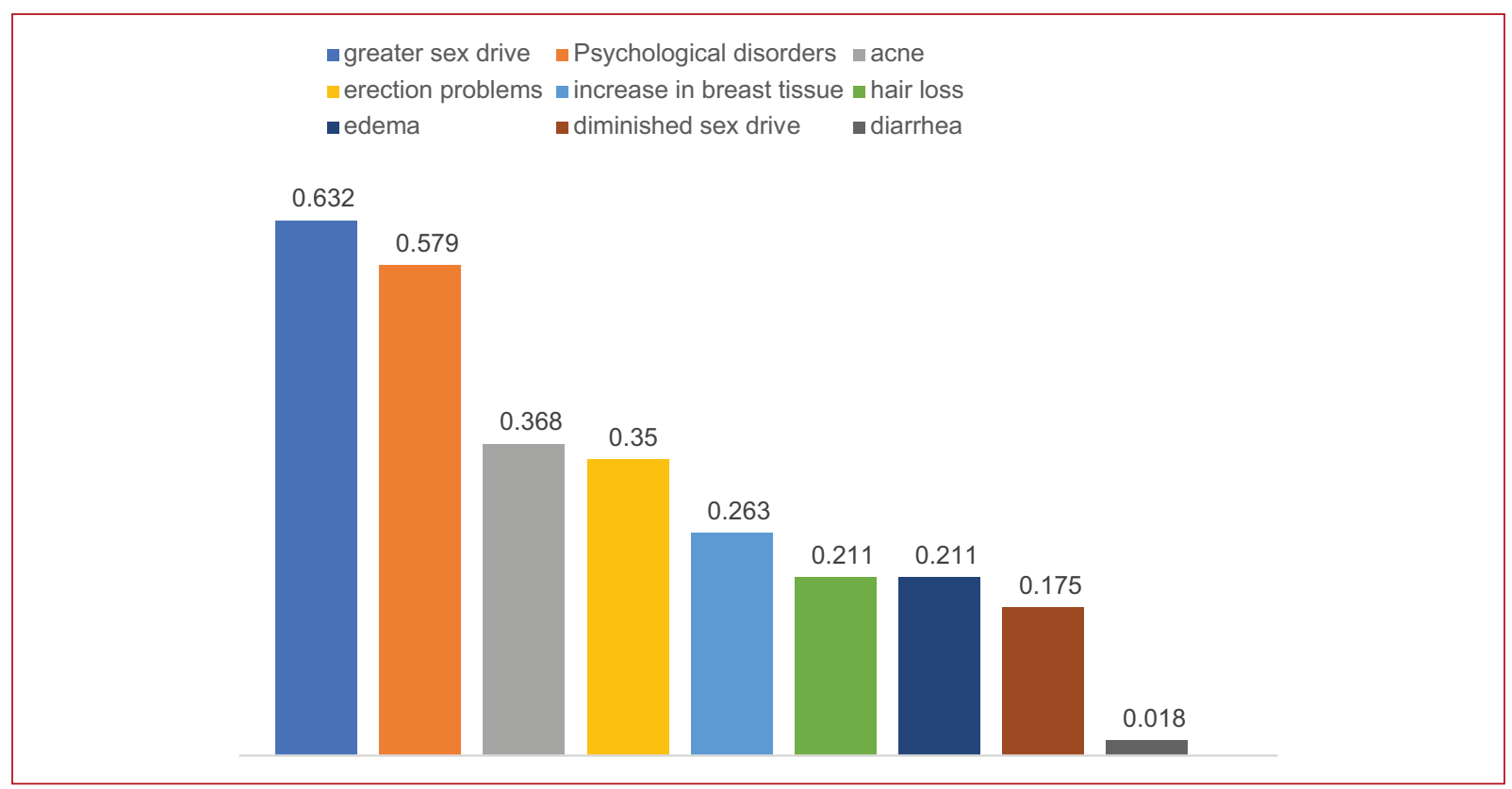

Figure 5. Adverse effects attributable to the use of steroids in study subjects. The number of responses is not equal to the number of respondents since users had the option to choose more than 1 answer. Therefore, the response rate may exceed $100 \%$.

In a similar study conducted among the Danish population, which was also an anonymous questionnaire between recreational users of AS, a prevalence of $15 \%$ was obtained, which suggests significant interest among our population in the study of the use of $\mathrm{AS}^{10}$.

In determining the reasons for the use of AS for bodybuilding, the main reasons which lead to the use of AS include physical improvement and to a lesser extent improving physical performance. Contrary to the study by Dunn et al. which suggests that the use of AS is part of the user's experimentation with other substances and desire to try new drugs ${ }^{1}$. This is a major reason among young consumers, especially adolescents, who place more importance on a good body image ${ }^{7}$. In the previous studies, a link between image perception and the use of ASs among gym users was detected; muscle dysmorphia has been described as a man with a disorder of his own perception and body image, characterized by a pathological preoccupation with muscular size, and this is linked to the abuse of androgenic ASs ${ }^{9}$.

In relation to other studies conducted in international publications about AS, the similarity of adverse effects stands out. Some of the psychological effects found in AS users include irritability, aggression, and changes in personality among users 6 . In other studies, there were differences, since they documented adverse effects in the liver, blood lipid levels, and alterations in the reproductive system, without specifying incidence or prevalence ${ }^{2}$. We were able to observe that most consumers presented adverse effects attributable to the use of AS in direct usage time effect. These side effects often corresponded to psychological disorders, such as mood swings, irritability, and/or depression. However, in a study by Salim et al., the most common adverse effects were acne, changes in voice, and aggressiveness? Based on this, we may consider that indiscriminate use could mean a greater negative impact on the already unstable and still in development psyche of adolescents, considered in this study to be at greater risk ${ }^{11}$.

The implication of adverse effects inherent to the use of AS opens new questions for future research into the perception of risk and the level of education presented by the general population about the use of these potentially damaging substances. Family problems, school dropouts, aggressiveness, and a greater probability of inappropriate conduct are some of the relevant consequences to take into consideration as arguments to take measures of prevention and education ${ }^{3}$.

The non-medical use of androgenic AS is a serious public health problem on the rise, as different studies show, just as ours, due to the high prevalence obtained 8 .

\section{Conclusion}

The present study found a high prevalence in the recreational use of androgenic ASs in the metropolitan 
area of Monterrey, personally referred by each subject surveyed, which highlighted the fact that due to its high consumption, it is becoming a health problem that requires continuation in medical research. The use of ASs is greater among the older population who attend these gyms, most of whom obtain their information through unreliable sources such as gym instructors or the internet. Psychological disorders represent the most relevant negative effects in the short term. Altogether, this justifies the need for a commitment from society in general to the prevention and education on the use of ASs.

\section{Conflicts of interest}

The authors declare that there is no knowledge of any conflicts of interest linked to this publication and that there is no significant financial support for the completion of this work which may have influenced it.

\section{Financing}

This study was conducted using the Department of Sports Medicine and Rehabilitation's own resources.

\section{Ethical disclosures}

Protection of human and animal subjects. The authors declare that no experiments were performed on humans or animals for this study.
Confidentiality of data. The authors declare that they have followed the protocols of their work center on the publication of patient data.

Right to privacy and informed consent. The authors declare that no patient data appear in this article.

\section{References}

1. Dunn M, White V. The epidemiology of anabolic-androgenic steroid use among Australian secondary school students. J Sci Med Sport. 2011;14:10-4.

2. Bahrke MS, Yesalis CE. Abuse of anabolic androgenic steroids and related substances in sport and exercise. Curr Opin Pharmacol. 2004:4:614-20.

3. Chirivella EC, Esquiva IC. El consumo de esteroides y su relación con variables psicológicas en practicantes de musculación. Health Addict Salud Drog. 2011;11:129-42.

4. Toward A, Among AS, Types V, Study C. Attitudes toward anabolic-androgenic steroids among non-competing athletes in various types of sports a cross-sectional study. 2013;22:109-28.

5. Acevedo P, Jorge JC, Cruz-Sanchez A, Amy E, Barreto-Estrada JL A ten-year assessment of anabolic steroid misuse among competitive athletes in Puerto Rico. West Indian Med J. 2011;60:531-5.

6. Sagoe D, Andreassen C, Pallesen S. The aetiology and trajectory of anabolic-androgenic steroid use initiation: a systematic review and synthesis of qualitative research. Subst Abuse Treat Prev Policy. 2014;9:27.

7. Salim O, Abrahin C, Souza SF, De Sousa EC, Kely J, Moreira R, et al. Prevalence of the use of anabolic androgenic steroids by physical education students and teachers who work in health clubs. Rev Bras Med Esporte. 2013;19:27-30.

8. Sagoe D, Molde $H$, Andreassen CS, Torsheim T, Pallesen S. The global epidemiology of anabolic-androgenic steroid use: a meta-analysis and meta-regression analysis. Ann Epidemiol. 2014;24:383-98.

9. Angoorani $\mathrm{H}$, Halabchi $\mathrm{F}$. The misuse of anabolic-androgenic steroids among Iranian re-creational male body-builders and their related psycho-socio-demographic factors. Iran J Public Health. 2015;44:1662-9.

10. Bojsen-Møller J, Christiansen AV. Use of performance- and image-enhancing substances among recreational athletes: a quantitative analysis of inquiries submitted to the Danish anti-doping authorities. Scand J Med Sci Sport. 2010;20:861-7.

11. Nilsson S, Baigi A, Marklund B, Fridlund B. The prevalence of the use of androgenic anabolic steroids by adolescents in a county of Sweden. Eur J Public Health. 2001;11:195-7. 